\title{
Evaluation of polyamide surgical mesh as an abdominal ventral implant in rabbits ${ }^{1}$
}

Renata Gebara Sampaio Dória', Silvio Henrique de Freitas", Yumi de Barcelos Hayasaka'", Maria Cristina Ferrarini Nunes Soares Hage ${ }^{\mathrm{lv}}$, Ricardo de Francisco Strefezziv , Adriano Bonfin Carregarovl, Gustavo Morandini Reginato ${ }^{\mathrm{VII}}$, Carlos Eduardo Ambrósio ${ }^{\mathrm{VIII}}$, Alois Foltran Müller ${ }^{\mathrm{Ix}}$

'MSc, PhD, Veterinary Medicine Department (ZMV), Faculty of Animal Sciences and Food Engineering (FZEA), Universidade de São Paulo (USP), Pirassununga-SP, Brazil. Conception and study of the design, technical procedures, acquisition and analysis of data, manuscript writing.

"MSc, PhD, Associate Professor, ZMV, FZEA, USP, Pirassununga-SP, Brazil. Acquisition of data, supervised all phases of the study.

I"Graduate student, ZMV, FZEA, USP, Pirassununga-SP, Brazil. English language, technical procedures.

${ }^{I V} \mathrm{MSc}, \mathrm{PhD}, \mathrm{ZMV}$, FZEA, USP, Pirassununga-SP, Brazil. Interpretation of data, manuscript preparation.

${ }^{V} \mathrm{MSc}, \mathrm{PhD}$, Associate Professor, ZMV, FZEA, USP, Pirassununga-SP, Brazil. Analysis of data, manuscript preparation.

VIMSc, PhD, Associate Professor, ZMV, FZEA, USP, Pirassununga-SP, Brazil. Design of the study, interpretation of data.

${ }^{V I I}$ Fellow Master degree, Postgraduate Program in Animal Bioscience, FZEA, USP, Pirassununga-SP, Brazil. Interpretation of data, manuscript writing.

VIIIPhD, Full Professor, DMV, FZEA, USP, Pirassununga-SP, Brazil. Technical procedures, acquisition and analysis of data, manuscript writing.

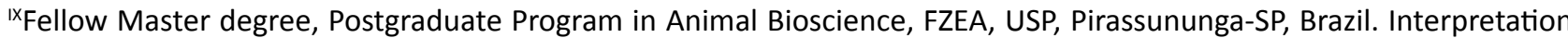
of data, manuscript preparation.

Abstract

Purpose: To evaluate abdominal ventral wound healing by using a specific biomaterial, a handmade polyamide surgical mesh.

Methods: A surgical incisional defect was made in ten rabbits to simulate a hernia in the ventral abdominal musculature. A polyamide surgical mesh was used in hernioplasty. They were monitored for surgical wound healing, and macroscopically and histologically evaluated at the end of the experiment. The polyamide surgical mesh did not cause foreign body reaction, pain, edema, or infection in the surgical site. The manure production was not affected by intestinal tissue adherences to the mesh, consistent with the ultrasonography result where adherences were not observed and organized scarring tissue formed in the incisional defect. The polyamide mesh was fixed over the abdominal wall, and its external and internal sides were surrounded by a vascularized connective tissue.

Results: None of the experimental animals developed adherences from internal organs to the polyamide mesh, except two rabbits where the omentum formed adherence to the internal scarring tissue without present herniation or compromise of the rabbit's health.

Conclusion: Polyamide surgical mesh for hernioplasty presents, in rabbits, excellent biocompatibility, with minimal body adverse reactions and low cost.

Key words: Biocompatible Materials. Surgical Mesh. Nylons. Hernia. Rabbits. 


\section{Introduction}

Hernias are organ protrusions surrounded by peritoneum through a natural hole. They have high incidences in people and domestic animals, and named in accordance with their localization. The most common are inguinal, scrotal, and umbilical hernias ${ }^{1}$. Incisional hernia consists of the viscera protrusion through areas of the abdominal wall abnormally weakened by trauma and surgical incisions ${ }^{2}$. Usually, the hernial sac has omentum, fat tissue, and intestinal tissue ${ }^{3}$.

Hernia repair is needed for patients that present aesthetic problems, intestinal obstruction, or acute strangulation ${ }^{2}$. The treatment is by surgical repair using herniorrhaphy ${ }^{1}$. Hernia recurrence is among the most troublesome outcomes after hernia repair, showing a progressive increase in recurrence after repeated repair ${ }^{4}$. Hernioplasty using surgical mesh has been used widely, and many different materials can be used that are resistant to infections, inert, and nonadherent, and that allow tissue vascularization in the injury site and mechanical stability ${ }^{5}$. Currently, the polypropylene surgical mesh is the standard material chosen in cases where the hernia cannot be reduced by sewing the edges of healthy muscle tissue together or when strain in the suture line is too much. The material reduces the dehiscence rate during the postsurgical period and the pain ${ }^{6}$. The benefits of polypropylene in comparison with biomaterials from animal tissues such as equine pericardium or equine central diaphragm tendon preserved in $98 \%$ glycerin are its resistance, absence of bioreactivity and degradation, and elasticity, which allows better equilibrium in the tension distribution. However, it is a high-cost option and can cause postsurgical complications such as infections, septicemia, intra-abdominal organ injury, and adherences ${ }^{7}$. Positioning the polypropylene mesh in direct contact with the intraperitoneal viscera can form adhesions and fistulas, which occur in $80-90 \%$ of human patients ${ }^{6,8}$.

Thus, this study presents a handmade mesh made with polyamide monofilament suture that could be used as a synthetic prosthetic material to repair hernia in domestic animals. Replacing polypropylene with polyamide as the mesh material for hernioplasty could be beneficial owing to lesser tissue reaction and the formation of adhesions once polyamide becomes biotolerable and inert, successful use in diverse tissue sutures, and lower cost than polypropylene ${ }^{9}$.

The present study was aimed at verifying the healing of a surgical defect created in the ventral abdominal wall of rabbits after hernia repair by using a specific biomaterial, a handmade polyamide monofilament surgical mesh.

\section{Methods}

This research was performed in accordance with the recommendations of the international guidelines for animal protection and approved by the Ethics Committee of Animal Use.

Ten rabbits $(n=10)$ from the order Lagomorpha, genera Oryctolagus, specie Oryctolagus cuniculus, breed New Zealand white, male, 4 months old, weighing between 3 and $4 \mathrm{~kg}$ were used in this study. They were fed with commercial feed for rabbits and water ad libitum.

A surgical square net $2.0 \mathrm{~cm}$ in width by $3.0 \mathrm{~cm}$ in length was handmade with a polyamide monofilament line (Araty: superflex $100 \%$ polyamide, yellow), $0.25 \mathrm{~mm}$ in diameter, with a 4-mm space between knots (Figure $1 \mathrm{~A})$. The mesh was autoclaved at $121^{\circ} \mathrm{C}$ for 30 minutes.

With the rabbits under general inhalatory anesthesia, positioned in dorsal 
recumbency, the hair clipped, and the ventral abdomen prepared for aseptic surgery, a skin incision was made, followed by undermining of the subcutaneous tissue to find the linea alba. An incisional scalpel defect of $15 \times 20$ $\mathrm{mm}$ was performed in the ventral abdominal musculature, involving the linea alba, right and left rectus abdominal muscles, and peritoneum, simulating an umbilical or incisional hernia. The mesh was placed over this tear (Figure 1B), and the margins were anchored in the external sheath of the rectus abdominal muscle with simple interrupted stitches by using polyamide monofilament 3-0 thread. Then, the subcutaneous tissue was sutured with continuous stitches of polyglycolic acid 3-0 thread; and the skin, with interrupted stitches of polyamide monofilament 3-0 thread.

The broad-spectrum antibiotics enrofloxacin $10 \mathrm{mg} / \mathrm{kg}$ intramuscularly and anti-inflammatory meloxicam $0.2 \mathrm{mg} / \mathrm{kg}$ subcutaneously for 5 days were administered. Rifampicin sodium spray was used topically in the surgical wound until complete healing. After 10 days of surgery, the skin stitches were removed.

Daily until 10 days after surgery, the animals were observed to evaluate the surgical site for signs of infection, swelling, pain, warmth, and secretion where the polyamide mesh was placed.

During 180 days, the ventral abdominal wall was inspected for hernia signs such as presence or absence of reducible volume. The intestinal abnormality caused by a possible adherence from intestinal tissue in the mesh was evaluated based on manure production and tenesmus.

An ultrasonographic examination from the ventral abdominal region was performed before surgery, after surgery, and 40,60, 120, and 180 days after surgery. The machine used was ESAOTE MyLabClassC VET and linear transducer probe LA435, at a frequency of $18 \mathrm{MHz}$.
At 6 months after surgery, the rabbits were anesthetized and euthanized, and necropsy was performed to evaluate the macroscopic aspects of surgery and to harvest material for histopathological examination. During macroscopic evaluation, we looked for adherences between organs and the polyamide mesh. Samples for histopathological examination should have a ventral abdominal wall with subcutaneous tissue, ventral abdominal musculature, surgical mesh, and peritoneum. Tissue fragments were fixed in $10 \%$ buffered formalin and stained with hematoxylin and eosin for histopathological evaluation.

\section{- Results}

All the rabbits had good surgical wound healing, without signs of infection, fistulous tract, hernia recurrence, or mesh extrusion. No seroma, hematoma, secretion, swelling, or warmth was found in the surgical site (Figure 1).

The macroscopic evaluation did not show local skin adverse reactions. The polyamide mesh over the created defect in the abdominal ventral musculature preserved the anatomy of the abdominal wall and barred the intra-abdominal organs to go through the created defect. The polyamide mesh was fixed over the abdominal wall, and its external side was surrounded by vascularized connective tissue (Figure 1C). A thin layer of a peritoneumlike tissue covered the internal side of the surgical mesh (Figure 1D). None of the experimental animals developed adherences of internal organs to the polyamide mesh, except two rabbits where the omentum formed adherence to the internal scarring tissue but without present herniation or compromise of the rabbit's health (Figure 1E).

Histopathological examination revealed minimal to absent inflammatory reaction at 
180 days after surgery. Small quantities of macrophages and fibroblasts surrounded the mesh, and no additional cell types or lesions were observed. Moreover, no marked difference was observed between the samples (Figure 1F).

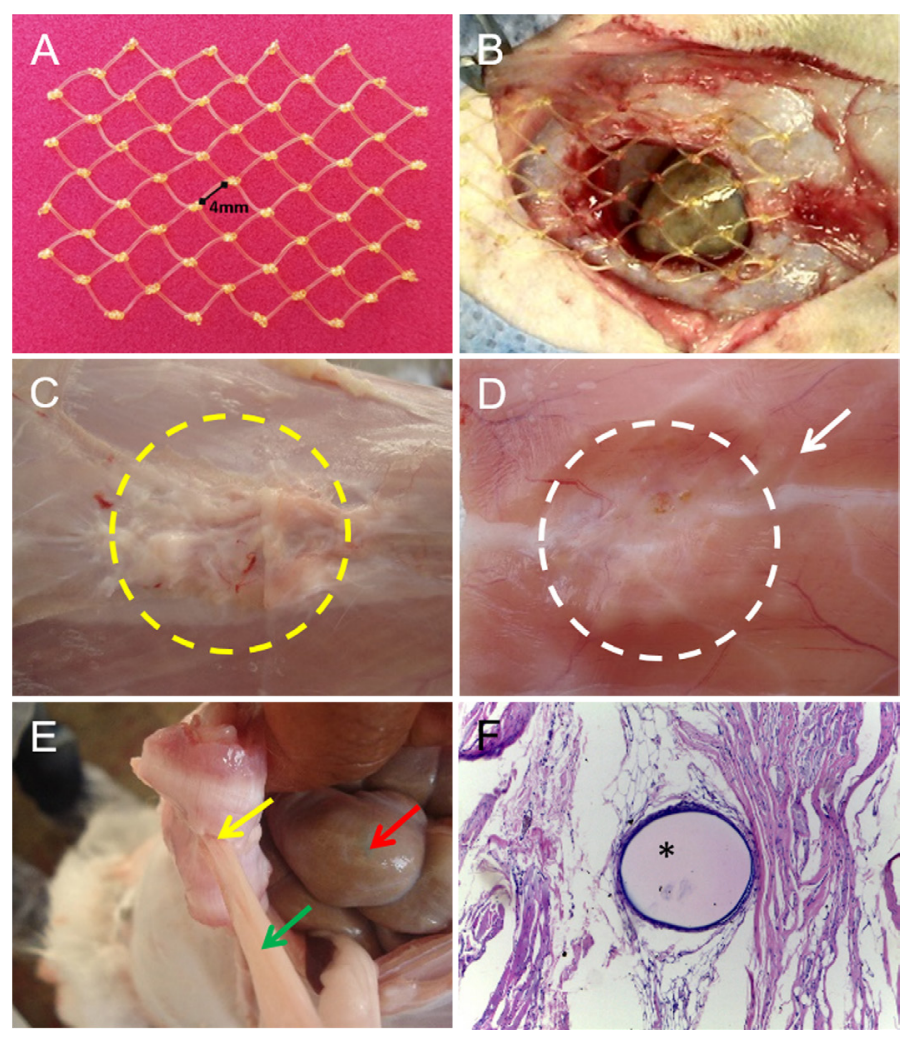

Figure 1 - Evolution of the surgical incisional defect created in the ventral abdominal musculature of rabbits repaired with polyamide mesh. The handmade polyamide mesh with $0.25-\mathrm{mm}$ diameter and 4-mm space between the knots (A). The polyamide surgical mesh over the created defect in the abdominal ventral musculature of a rabbit during the transoperative phase (B). External abdominal ventral musculature view showing the polyamide mesh totally covered by connective tissue (yellow dotted circle) (C). Internal abdominal ventral musculature view showing the polyamide mesh totally covered by a peritoneum-like tissue (white dotted circle) and the peritoneum (white arrow) (D). Adherence between the omentum (green arrow) and the healed ventral musculature defect (yellow arrow), but no adherence to intestinal tissue (red arrow) (E). Photomicrograph of the abdominal ventral musculature showing in the transversal cut the monofilament polyamide suture $\left({ }^{*}\right)$ surrounded by fibroblast. Hematoxylin and eosin staining, original magnification $\times 40(F)$.

The ultrasonographic examination result did not suggest rejection of the polyamide mesh or adherences. The examination was helpful to follow up the healing process, confirm the right placement of the mesh, identify the incisional defect by depth, and characterize the tissue surrounding the mesh during the postsurgical period. The ultrasonography image showed that the mesh could be identified by period-comma echogenic lines with acoustic shadows produced by suture and mesh knots. No echogenicity changes were observed in the polyamide material, which suggested integrity of the material. By the natural movement of the organs during breathing (the peritoneum sliding against the abdominal muscle, or "sliding sign"), we concluded no adherences. The healing 
tissue that filled the gap between the muscle edges had a heterogenic areas interspersed with hyperechoic and hypoechoic areas. This suggested formation of scarring tissue ${ }^{10}$. In the comparison between the immediate and 180day postsurgical examinations, we observed a constant tissue organization until a plateau at 120 days after surgery. Between 120 and 180 days, we found only few alterations. At 180 days, all the animals had the same type of healing tissue on ultrasonographic examination (Figure 2).

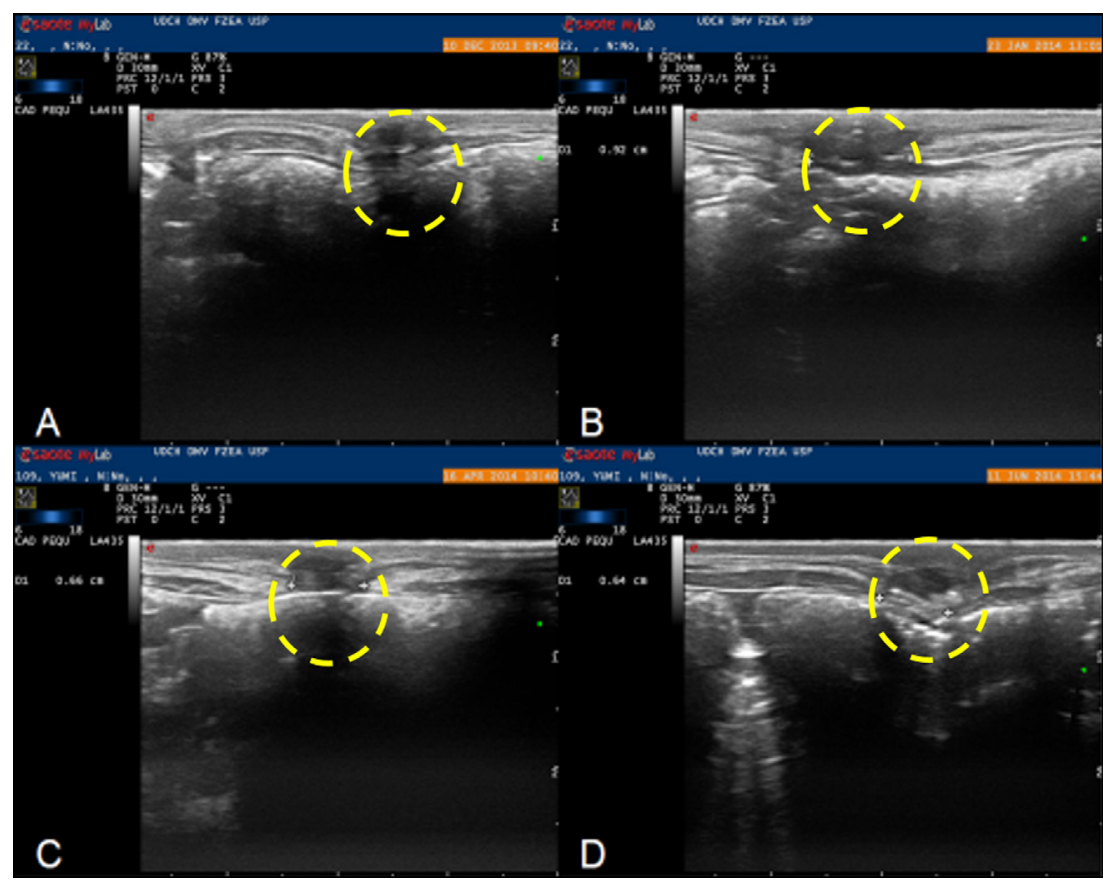

Figure 2 - Transversal ultrasonographic image of the monofilament polyamide surgical mesh over the incisional defect in the abdominal ventral muscle of rabbits in the immediate (A), 40-day (B), 120-day (C), and 180-day postsurgical period (D). The yellow circle shows the progress of the healing process.

\section{- Discussion}

The present study aimed to evaluate the polyamide monofilament surgical mesh as a better economic choice, with less infection rate and less inflammatory reaction in abdominal hernia repair surgery.

Hernia repair surgery can be performed by apposition and suturing of the edges of the defect (herniorrhaphy), but approximately $31 \%$ to $55 \%$ of repairs made without the use of prostheses may cause recurrence in humans ${ }^{8}$. Another technique is to use natural biomaterials such as equine pericardium or equine diaphragm tendon central preserved in $98 \%$ glycerin or synthetic biomaterials such as polypropylene surgical mesh to fix the defect or to reinforce the herniorrhaphy suture ${ }^{11}$. In this study, the polyamide mesh proved to be a good synthetic option, being less expensive and presenting good results. It ensured the mechanical support to abdominal organs without exacerbated inflammatory reactions or induced reaction against a foreign body.

Some of the characteristics of the synthetic mesh should be evaluated prior to the experimental use because they can influence the interaction between the mesh 
and holster tissues. The biomaterial weight, fiber composition, and size of the gap are some of important properties to check. The material weight is measured in grams per square meter, and light materials are the ideal. Light materials will be less aggressive and less reactive. Fiber composition can be chosen between monofilament or multifilament, and coated or uncoated.

The multifilament tends to be prone to bacterial infection requiring more care during postsurgery. In some cases, removal of the mesh, the infection origin, is required because antibiotic therapy alone cannot control the infection. The size of the gap is directly related to the induction of healing process and reduction of infection rate. Meshes with gaps equal or greater than $100 \mu \mathrm{m}$ are better because healing and immune cells have easier access to the injured site $^{2}$. The mesh used in this study was handmade with polyamide, monofilament, and a thickness of $0.25 \mathrm{~mm}$, and the gap of $4 \mathrm{~mm}$ between the knots presented good proprieties and effectively corrected the hernia in the experimental rabbits.

A mesh should be biocompatible, non-antigenic, and have a three-dimensional structure with adequate porosity and pore size $^{12}$. The effects of pore size on tissue regeneration have been emphasized by experiments demonstrating an optimum pore size of $5 \mu \mathrm{m}$ for neovascularization and 5-15 $\mu \mathrm{m}$ for fibroblast ingrowth ${ }^{13}$. Pore interconnectivity is also critical to ensure the blood supply to cells for mass transfer of oxygen and nutrients to the tissues, avoiding the implanted material rejection ${ }^{14}$. The present study verified that the polyamide mesh conformed to the ideal principles of a surgical mesh, allowing the adhesion and proliferation of the fibroblastic cells embedded on the mesh or cell migration from the surrounding tissue ${ }^{12}$. This scarring tissue totally wrapped the polyamide mesh, ensuring mechanical support to the defect created in the musculature, without exhibiting tecidual reaction to the implanted material.

Another complication factor in hernioplasty using mesh is the adherence after the procedure ${ }^{2}$, which is one of the most important reasons for a second celiotomy ${ }^{15}$ because the adherences can cause intestinal obstruction and pain ${ }^{16-18}$. The role of intestinal adherences is not well explained, but ischemia, trauma, inflammation, hemorrhage, genetic predisposition, and foreign body reaction are possibly related ${ }^{16,19}$. These factors can stimulate abnormal scar healing process with intense deposition of extracellular membrane and increase fibrin synthesis by inflammatory cells that function to repair and attach tissues that create the adherences ${ }^{15,19-21}$. In this study, the adherences between internal organs, especially the intestine, and the mesh were not seen. However, in two rabbits, the omentum attached to the mesh. This means that our mesh had minimum tissue reaction ${ }^{9}$ being incorporated by the organism involved by adjacent soft tissue. The collagen covering the polyamide mesh seems to confer important advantages in biocompatibility terms, with beneficial implications to the formations of adhesions $^{22}$.

Currently, the polypropylene mesh is the most frequent choice to hernioplasty in humans and animals. However, some clinicians reported complications related with polypropylene mesh, such as sepsis, intra-abdominal organ erosion, and fistula ${ }^{6}$. Complications are commonly observed when the mesh is intraperitoneally inserted, but also observed when the mesh is inserted extraperitoneally ${ }^{1}$. When the polyamide mesh was used in this study, extraperitoneally but in contact with abdominal organs, complications were not reported in rabbits during the experiment. This reinforces the concept that the polyamide mesh is a good option, bioinert, and biocompatible. 
Similarly, surgery wound infection or expulsion of mesh in the abdominal subcutaneous tissue was not observed, which suggests that this mesh can also be used in excisional surgical wounds. The surgical monofilament polyamide mesh was well accepted in rabbits and did not show any foreign body reaction or infections. It occurs probably because of polyamide proprieties. It has adequate tension, relative inertness, low related local inflammatory reaction, no capillary action, and can be used in almost all tissues $^{9}$. This fact could be demonstrated by histopathological examination 180 days after surgery, where the polyamide suture after fixed in tissue induced small inflammation with macrophages and fibroblast involved the mesh. The mesh was not structurally affected, which means that the healing process was good.

After macroscopic evaluation, and ultrasonographic and histopathological examinations, we observed in this study a perfect surgical wound healing, correction, and support of abdominal defect without any exacerbated tissue reaction, even 6 months after surgery.

\section{Conclusion}

Polyamide surgical mesh for hernioplasty presents, in rabbits, excellent biocompatibility, with minimal body adverse reactions and low cost.

\section{References}

1. Bringman S, Conze J, Cuccurullo D, Deprest J, Junge K, Klosterhalfen B, Parra-Davila E, Ramshaw B, Schumpelick V. Hernia repair: the search for ideal meshes. Hernia. 2010;14(1):81-7. doi: 10.1007/s10029-0090587-x.

2. Schreinemacher MHF, Emans PJ, Gilbels MJJ, GreveJWM, Beets GL, Bouvy ND. Degradation of mesh coatings and intraperitoneal adhesion formation in an experimental model. Br J Surg. 2009;96(3):305-13. doi: 10.1002/bjs.6446.

3. Sutradhar BC, Hossain MF, Das BC, Kim $G$, Hossain MA. Comparison between open and closed methods of herniorrhaphy in calves affected with umbilical hernia. J Vet Sci. 2009;10(4):343-47. PMID: 19934601.

4. Flum DR, Horvath K, Koepsell T. Have outcomes of incisional hernia repair improved with time? A population-based analysis. Ann Surg. 2003;237(1):129-35. doi: 10.1097/01.SLA.0000041042.86225.9C.

5. Trindade EN, Trindade MRM. 2010. Uso de telas na cirurgia da hérnia inguinal. Rev Assoc Med Bras. 2010;56(2):139. doi: 10.1590/S0104-42302010000200007.

6. Aramayo ALG, Lopes Filho GJ, Barbosa CA, Amaral VF. Abdominal wall healing in incisional hernia using different biomaterials in rabbits. Acta Cir Bras. 2013;28(4):307-16. doi: 10.1590/S0102-86502013000400011.

7. Pereira-Lucena CG, Artigiani Neto $R$, De Rezende DT, Lopes-Filho GJ, Matos D, Linhares MM. Early and late postoperative inflammatory and collagen deposition responses in three different meshes: an experimental study in rats. Hernia. 2014;18(4):563-70. doi: 10.1007/s10029013-1206-4.

8. Gaertner WB, Bonsack ME, Delaney JP. Visceral adhesions to hernia prostheses. Hernia. 2010;14(4):375-81. doi: 10.1007/ s10029-010-0659-y.

9. Ribeiro $C M B$, Silva Júnior VA, Silva Neto JC, Vasconcelos BCE. Estudo clínico e histopatológico da reação tecidual às suturas interna e externa dos fios monofilamentares de nylon e poliglecaprone 25 em ratos. Acta Cir Bras. 2005;20(4):284-91. doi: 10.1590/ S0102-86502005000400005.

10.Küllmer K, Sielver KW, Rompe JD, Nägele M, Harland U. Sonography and MRI of experimental muscle injures. Arch Orthop Trauma Surg. 1997;116(6-7):357-61. doi: 10.1007/BF00433990.

11.Stopiglia AJ, Matera JM, Fantoni DT, Sterman FA, Lacerda PMO. Avaliação do tratamento cirúrgico da hérnia perineal em cães com o reforço de membrana de pericárdio equino preservado em glicerina a $98 \%$. Braz J Vet Res Anim Sci. 2011;48(3):220-27. doi: $10.11606 / \mathrm{S} 1413-95962011000300006$.

12.Angulo DEL, Sobral PJA. Characterization 
of gelatin/chitosan scaffold blended with aloe vera and snail mucus for biomedical purpose. Int J Biol Macromol. 2016;92:64553. doi: 10.1016/j.ijbiomac.2016.07.029.

13.Brauker JH, Carr-Brendel VE, Martinson LA, Crudele J, Johnston WD, Johnson RC. Neovascularization of synthetic membranes directed by membrane micro architecture. J Biomed Mater Res. 1995;29(12):1517-24. doi: 10.1002/jbm.820291208.

14.Yang S, Leong KF, Du Z, Chua CK. The design of scaffolds for use in tissue engineering. Part I: traditional factors. Tissue Eng. 2001;7(6):679-89. doi: $10.1089 / 107632701753337645$.

15.Kelmer G. Update on recent advances in equine abdominal surgery. Vet Clin $\mathrm{N}$ Am Equine Pract. 2009;25(2):271-82. doi: 10.1016/j.cveq.2009.04.007.

16.Cheong Y, Laird S, Li T, Shelton J, Ledger W, Cooke I. 2001. Peritoneal healing and adhesion formation/reformation. Hum Reprod Update. 2001;7(6):556-66. PMID: 11727864.

17. Ergul E, Korukluoglu B. Peritoneal adhesions: facing the enemy. Int J Surg. 2008;6(3):25360. doi: 10.1016/j.ijsu.2007.05.010.
18.Gorvy DA, Barrie EG, Proudman CJ. Intra-abdominal adhesions in horses: a retrospective evaluation of repeat laparotomy in 99 horses with acute gastrointestinal disease. Vet J. 2008;175(2):194-201. doi: 10.1016/j. tvjl.2007.02.016.

19. Ward BC, Panitch A. Abdominal adhesions: current and novel therapies. J Surg Res. 2011;165(1):91-111. doi: 10.1016/j. jss.2009.09.015.

20.Boland GM. Weigel RJ. Formation and prevention of postoperative abdominal adhesions. J Surg Res. 2006;132:3-12. doi: 10.1016/j.jss.2005.12.002.

21.Claunch K, Mueller P. Treating intraabdominal adhesions: the surgeon's dilemma. Equine Vet Educ. 2012;24(1):5525. doi: 10.1111/j.2042-3292.2012.00438.x.

22.Shug-Pass C, Sommerer F, Tannapfel A, Lippert $\mathrm{H}$, Kockerling $\mathrm{F}$. The use of composite meshes in laparoscopic repair of abdominal wall hernias: are there differences in biocompatibility? Experimental results obtained in a laparoscopic porcine model. Surg Endosc. 2009;23(3):487-95. doi: 10.1007/s00464-008-0085-8.

\section{Correspondence:}

Silvio Henrique de Freitas

Faculdade de Zootecnia e Engenharia de Alimentos

Departamento de Medicina Veterinária, USP

Rua Duque de Caxias Norte, 225

13635-900 Pirassununga - SP Brasil

Tel.: (55 19)3565-6881

silviohfreitas@gmail.com

Received: Jan 26, 2018

Review: Mar 27, 2018

Accepted: Apr 25, 2018
Conflict of interest: none

Financial sources: PIBIC-CNPq and FAPESP 